\title{
Formation of potentially toxic carbonyls during oxidation of triolein in the presence of alimentary antioxidants
}

\author{
Marini Damanik $^{1}$ (D) Michael Murkovic $^{1}$
}

Received: 11 May 2017 / Accepted: 10 July 2017/Published online: 19 October 2017

(c) The Author(s) 2017. This article is an open access publication

\begin{abstract}
A relation between oil uptake and cancer as well as induction of hepatic inflammation was shown earlier. It is discussed that the main oil oxidation products-hydroperoxides and carbonyls-might be the reason for the mentioned diseases. In this manuscript quantitative determination of aldehydes which are formed during oxidation of triolein-as a model substance-using the Rancimat 679 is described. The oxidation of $11 \mathrm{~g}$ of triolein is carried out at $120{ }^{\circ} \mathrm{C}$ sparging air with a flow of $20 \mathrm{dm}^{3} / \mathrm{h}$ for $10 \mathrm{~h}$. A series of aliphatic aldehydes starting from hexanal to decanal as well as decenal was identified by LC-MS/MS and quantified as DNPH derivatives. In addition, the total amount of carbonyls was determined. Based on the calibration with hexanal, all other dominant substances were in the similar concentration range with maximum concentrations of $1.6 \mu \mathrm{mol} / \mathrm{cm}^{3}$ of hexanal, $2.3 \mu \mathrm{mol} / \mathrm{cm}^{3}$ of heptanal, $2.5 \mu \mathrm{mol} / \mathrm{cm}^{3}$ of octanal, $3.2 \mu \mathrm{mol} / \mathrm{cm}^{3}$ of nonanal, $4.0 \mu \mathrm{mol} / \mathrm{cm}^{3}$ of decanal after $6 \mathrm{~h}$. The total amount of carbonyls reached a maximum after $6 \mathrm{~h}$ being $27 \mu \mathrm{mol} /$ $\mathrm{cm}^{3}$ for triolein without antioxidant. The results of this investigation will be a basis for further toxicological studies on oxidized oils.
\end{abstract}

Marini Damanik

marini.damanik@student.tugraz.at

1 Institute of Biochemistry, Graz University of Technology, Graz, Austria
Graphical abstract

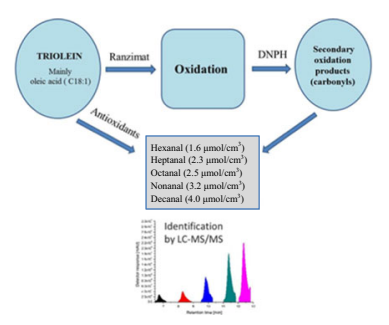

Keywords Triolein - Lipid oxidation - Aldehydes · DNPH $\cdot$ Antioxidants $\cdot \beta$-Carotene $\cdot \alpha$-Tocopherol

\section{Introduction}

Prolonged exposure to oxidized lipids can be detrimental to human health. It has been reported that lipid hydroperoxides from processed dietary oils can enhance the growth of hepatocarcinoma cells [1]. Another issue was published by Böhm and co-workers [2] who found that oxidized fat might result in liver inflammation which was shown in experimental rats. In the latter publication, no relation to a specific substance or group of substances was established. Therefore, a quantitative characterization of oxidized oils is a prerequisite to start further mechanistic investigations on the toxic principles of oxidized oils.

In earlier manuscripts the formation of different peroxides (hydroperoxides, epidioxides) and epoxides was described in detail [3, 4]. A second group of reactive products from oil oxidation are the carbonyls which are formed during further reactions of the primary peroxides.

The formation of carbonyls during oil oxidation was investigated earlier in rapeseed oil [5] when it was shown that as a result of the degradation of the intermediate 
hydroperoxides a great variety of aldehydes and ketones are formed. It is well known that medium and short chain aldehydes which are formed from higher unsaturated fatty acids are the key aroma-active components which are responsible for a rancid aroma. These are $\mathrm{C}_{7}-\mathrm{C}_{11}$ monounsaturated aldehydes, or $\mathrm{C}_{6}-\mathrm{C}_{9}$ dienals, or $\mathrm{C}_{5}$ branched aldehydes or some $\mathrm{C}_{8}$ ketones which are important contributors to the oil aroma having negative attributes (rancid, winey-vinegary, fusty, muddy sediment, musty) [6].

These carbonyls and other compounds such as aldehydes, terminal alkenes, carboxylic acids, and aliphatics are formed by a $\beta$-cleavage of lipid alkoxyl radicals [7]. The fragmentation reactions of allylic hydroperoxides by the Hock rearrangement create two different carbonyls from the same lipid peroxide, i.e. aldehydes or ketones [8]. Mechanistically, this is achieved by the insertion of one oxygen atom into the lipid carbon backbone and delocalization of a positive charge on a carbon or oxygen atom.

The main aim of this work was to establish an analytical method for a quantitative determination of the carbonyls in the lipid (oxidized oil) phase for determination of the alimentary exposure. For the easier identification and assignment of the reaction products, a defined matrix (triolein) which did not contain any interfering compounds was used. It was decided to use the derivatization with 2,4dinitrophenylhydrazine (DNPH) — a commonly known derivatization reagent for carbonyls-that would give the possibility to identify and quantify single components as well as the total carbonyl content. These derivatives are stable and can be analysed by HPLC with ESI-MS in the negative mode or by its absorption at $400 \mathrm{~nm}$ [9-11].

With this background, we have started to characterize the formation of carbonyls during oxidation of triolein in the oil phase and not the volatile phase in which these compounds are mostly related to sensory sensation. On basis of reversed phase chromatography with UV and MS detection, the non-evaporating carbonyl compounds formed during oxidation of triolein were identified and quantified. In this case, triolein was used as model oil. The results of these experiments will be a basis for future work on food oil oxidation. In addition, the interaction of antioxidants ( $\beta$-carotene, $\alpha$-tocopherol) with the carbonyl formation was analysed.

\section{Results and discussion}

\section{Secondary oxidation products analysis}

The derivatization of carbonyls is commonly used in chromatographic analysis. The hydrazones formed are stable enough for MS experiments. In some cases the

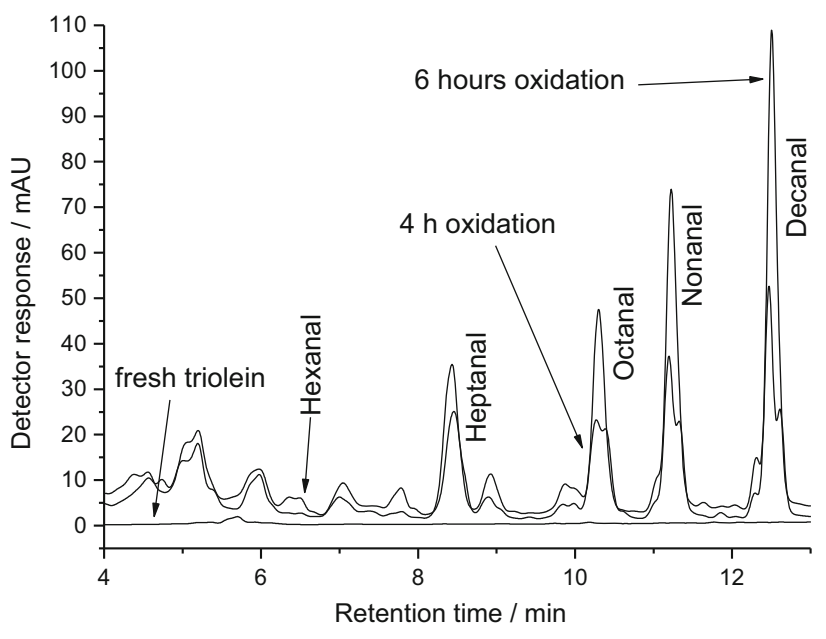

Fig. 1 Chromatogram of DNPH derivatives of fresh triolein and after $4 \mathrm{~h}$ as well as $6 \mathrm{~h}$ of oxidation in the Rancimat

carbonyls from fatty acid oxidation are too volatile to be analysed by LC/MS. Therefore, the DNPH adds molecular weight to increase sensitivity and selectivity [12]. Negative ionization using APCI was the most sensitive MS method which could be used. The hydrazones formed were analysed using visible light absorption (400 nm) or by MS. The advantage of detection at $400 \mathrm{~nm}$ is that practically all peaks that appeared in the chromatogram were DNPH derivatives. In the control chromatograms only the baseline could be observed at $400 \mathrm{~nm}$ (Fig. 1). The semiquantitative evaluation of the carbonyls was based on a calibration using hexanal with the peak area relating to the molar concentration of hexanal. The linear calibration of hexanal was done in the range of $8-1000 \mu \mathrm{g} / \mathrm{cm}^{3}(0.08-10 \mathrm{mM})$. The formation of carbonyls could be explained by a Hock cleavage which was reviewed by [7]. This might explain the formation of, e.g. decanal and 2-undecenal which are produced by homolytic cleavages on either sides of the 8-hydroperoxide and nonanal from either the 9- or 10-hydroperoxide. The linearity of the hexanal analysis was tested in the range of $5-1300 \mu \mathrm{g} / \mathrm{cm}^{3}$ according to Mandel [13] with a limit of detection of $4.1 \mu \mathrm{g} / \mathrm{cm}^{3}$ and a limit of quantification of $13 \mu \mathrm{g} / \mathrm{cm}^{3}$.

The formation of carbonyls began after $2 \mathrm{~h}$ of oxidation at $120{ }^{\circ} \mathrm{C}$ while bubbling air through the oil. A strong increase of carbonyl formation was observed between 2 and $4 \mathrm{~h}$ with a maximum after $6 \mathrm{~h}$ and a slight decrease or constant concentrations afterwards. A series of linear aldehydes (from 6 carbons to 10 carbons) could be identified positively by LC-MS. Based on the calibration with hexanal all other dominant substances were in the similar concentration range with maximum concentrations of $1.6 \mu \mathrm{mol} / \mathrm{cm}^{3}$ of hexanal, $2.3 \mu \mathrm{mol} / \mathrm{cm}^{3}$ of heptanal, $2.5 \mu \mathrm{mol} / \mathrm{cm}^{3}$ of octanal, $3.2 \mu \mathrm{mol} / \mathrm{cm}^{3}$ of nonanal, $4.0 \mu \mathrm{mol} / \mathrm{cm}^{3}$ of decanal after $6 \mathrm{~h}$ (Fig. 4). These identified 


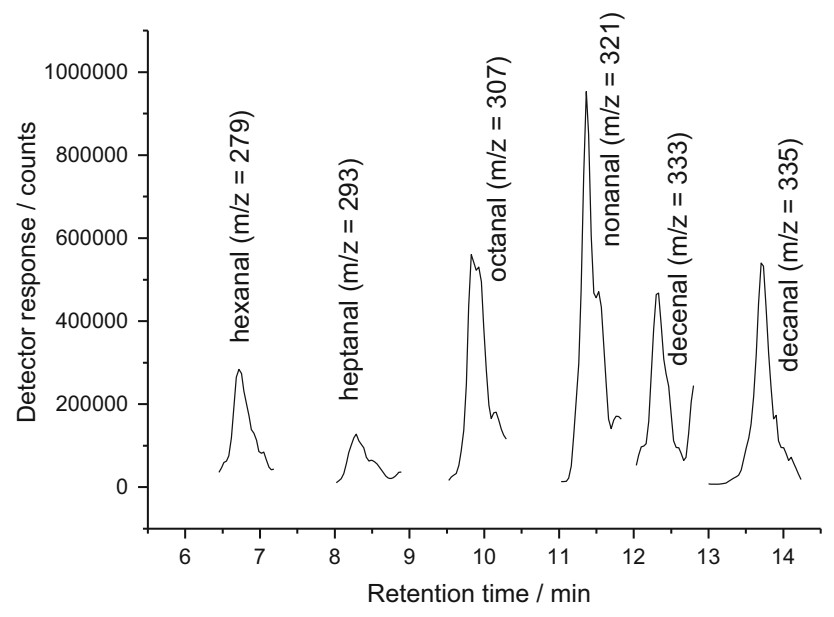

Fig. 2 Selected ion traces of the DNPH conjugates of the saturated and unsaturated aldehydes found in oxidized triolein

aldehydes were volatile and undergo further degradation reactions which may explain the reduced concentration.

The double peaks which could be seen after $4 \mathrm{~h}$ of oxidation were attributed to $Z / E$ isomer formation since no difference in the mass spectrum and UV absorption could be observed. After $6 \mathrm{~h}$ of oxidation the double peaks disappear resulting in a shift in the relative concentrations (Fig. 1).

The identification of the peaks was done by LC-MS/MS as is shown in Fig. 2. The earlier mentioned saturated aldehydes (hexanal-decanal) including decenal could be identified. The fragmentation of all of these compounds was similar with a specific fragment of $\mathrm{m} / \mathrm{z}=182$ originating from the DNPH moiety.

In this experiment, nonanal and octanal were the main products. 2-Nonenal and 2,4-decadienal which are the known degradation products of linoleic acid were not detected. Additional compounds (heptane, heptanol, octane, 1-undecene, and 2-undecenal) that were described earlier are produced by a homolytic fission of the intermediary formed R-O bond [14-19]. However, noncarbonyls could not be detected with the method described here.

The total amount of carbonyls formed is shown in Fig. 3. Similar to the single aldehydes, a maximum concentration is reached after $6 \mathrm{~h}$ with a decrease afterwards. The maximum concentration is $27 \mathrm{mM}$ which is based on a calibration with hexanal.

\section{Influence of lipid-soluble antioxidants on carbonyl formation}

In a second series of experiments, two lipid-soluble antioxidants were added, namely $\alpha$-tocopherol and $\beta$-carotene. The earlier experiments showed that the best

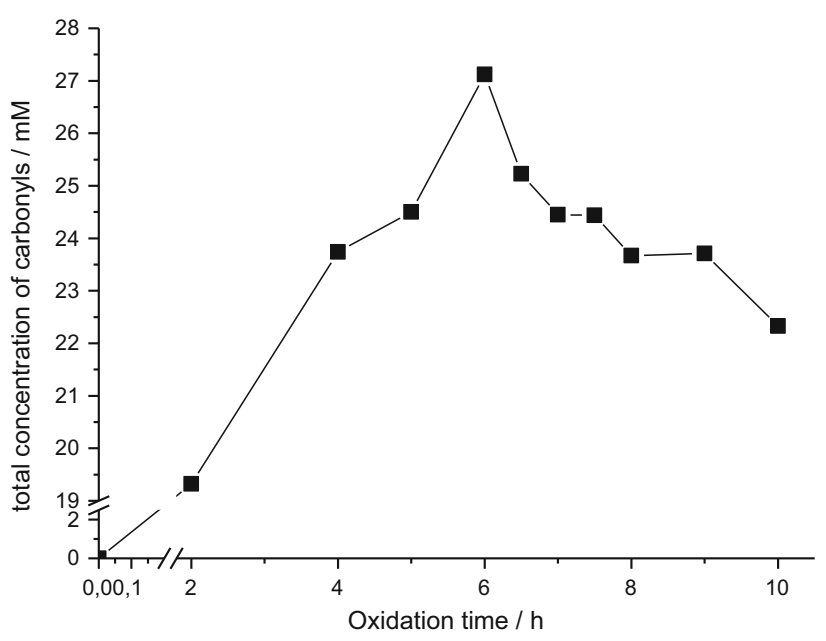

Fig. 3 Formation of the total amount of carbonyls during oxidation of triolein at $120{ }^{\circ} \mathrm{C}$ with constant air sparging

stabilization was obtained by addition of $300 \mathrm{ppm}$ of ascorbyl palmitate to soybean oil (SO). In addition, a combination of ascorbyl palmitate (300 ppm) and $\alpha$-tocopherol (1000 ppm) was able to limit hydroperoxide and hexanal formation in $\mathrm{SO}$ at $35^{\circ} \mathrm{C}$ for 12 weeks [20].

Antioxidants inhibit lipid oxidation by quenching free radicals and physically stabilizing the micelles at reaction sites [21]. As described in [22] the oxidation starts after $5 \mathrm{~h}$ in both, the refined and fortified oils (containing $\beta$-carotene), with the formation of hydroperoxides. In this case, the addition of $\beta$-carotene resulted in a pro-oxidant effect.

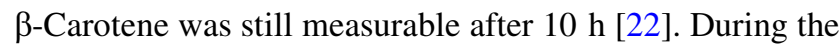
course of the oxidation in the experiments described here, the levels of the formed carbonyls were lower in the samples with added antioxidants (Fig. 4). In addition, the pattern of the chromatograms did not change significantly

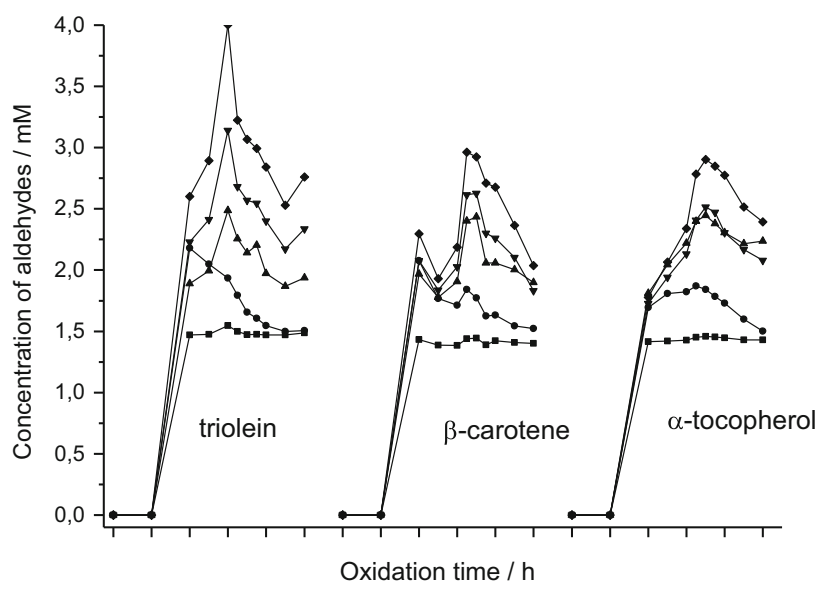

Fig. 4 Formation kinetics of single compounds during oxidation of triolein in presence of lipid-soluble antioxidants at $120{ }^{\circ} \mathrm{C}$ with constant air sparging for $10 \mathrm{~h}$ (filled circle hexanal; filled square heptanal; filled upward triangle octanal; filled downward triangle nonanal; filled diamond decanal) 


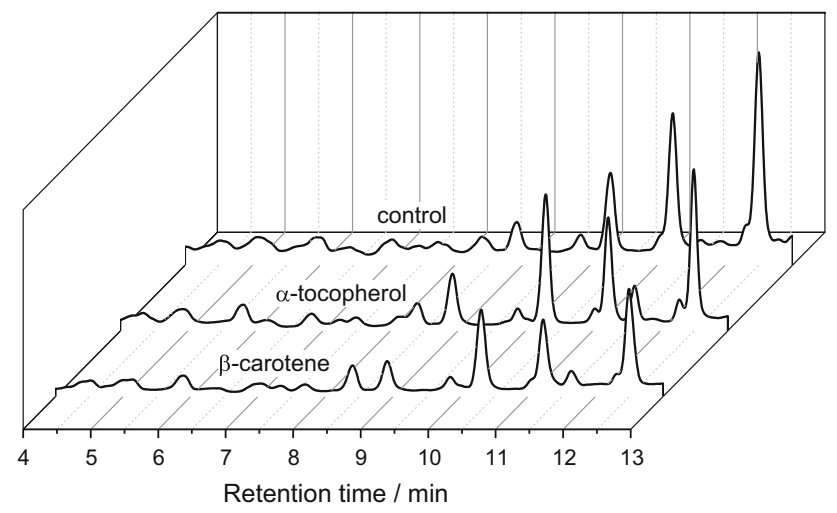

Fig. 5 Comparison of the carbonyl formation in presence of lipidsoluble antioxidants ( $\alpha$-tocopherol, $\beta$-carotene) after $10 \mathrm{~h}$ of oxidation at $120{ }^{\circ} \mathrm{C}$. The carbonyls are measured as DNPH derivatives detected at $400 \mathrm{~nm}$

indicating the same carbonyls are formed but at lower amounts. The sample containing $\alpha$-tocopherol showed a higher formation of octanal after $10 \mathrm{~h}$ (Fig. 5).

For this, $\beta$-carotene and $\alpha$-tocopherol were dissolved in acetone and added to the triolein. The concentrations of the antioxidants were $300 \mu \mathrm{g} / \mathrm{g} \pm 0.5 \mu \mathrm{g}$. The fortified triolein was stirred for $15 \mathrm{~min}$ and then flushed with nitrogen for $30 \mathrm{~min}$ to remove the acetone before sealing airtight in glass bottles. For the oxidation in the Rancimat $20 \mathrm{~g}$ of triolein was used. The concentrations which were applied were in the same range as it can be expected in natural oils. The $\alpha$-tocopherol concentration was $300 \mu \mathrm{g} / \mathrm{g}$ and the level of $\beta$-carotene was $500 \mu \mathrm{g} / \mathrm{g}$. The concentrations were selected according to the concentrations normally occurring in red palm oil which are in the range of $600-1000 \mu \mathrm{g} /$ $\mathrm{g}$ for vitamin $\mathrm{E}$ and $400-3500 \mu \mathrm{g} / \mathrm{g}$ for $\alpha$ - and $\beta$-carotene [23].

\section{Conclusion}

The formation of carbonyls was quantified during oxidation of triolein by derivatization of the formed products with DNPH which is a selective reagent for aldehydes and ketones. Some of the oxidized fragments of triolein were identified by LC-MS/MS - using APCI in negative mode-being hexanal $(\mathrm{m} / \mathrm{z}=279)$, heptanal $(\mathrm{m} / \mathrm{z}=293)$, octanal $(\mathrm{m} / \mathrm{z}=307)$, nonanal $(\mathrm{m} / \mathrm{z}=321)$, decenal $(\mathrm{m} /$ $z=333)$, decanal $(\mathrm{m} / \mathrm{z}=335)$, and undecenal $(\mathrm{m} /$ $z=347$ ). Using a Rancimat for reproducible oxidation experiments with a constant air flow at defined temperatures $\left(120^{\circ} \mathrm{C}\right)$ the production of carbonyls showed a good repeatability. The formation of carbonyls from triolein showed a maximum after $6 \mathrm{~h}$ with a slight or no decrease during prolonged oxidation.

\section{Experimental}

2,4-Dinitrophenylhydrazine (2,4-DNPH) was purchased from Sigma-Aldrich (St. Louis, USA), hydrochloric acid $(\mathrm{HCl}, 37 \%)$ was purchased from Merck (Darmstadt, Germany), all solvents (e.g. methanol, ACN, acetone) used were of HPLC grade and were purchased from Merck (Darmstadt, Germany), acetic acid was purchased from Roth (Karlsruhe, Germany), triolein was purchased from FLUKA (Buchs, Switzerland), $\beta$-carotene and $\alpha$-tocopherol were from Sigma-Aldrich (St. Louis, USA).

\section{Analysis of secondary oxidation products in oil}

\section{Oxidation of triolein with Rancimat}

The triolein oil samples were subjected to oxidation in a Rancimat (679, Metrohm, Herisau, Switzerland). Eleven grammes of sample was used for the oxidation experiments. The temperature was set to $120{ }^{\circ} \mathrm{C}$ and the air flow to $20 \mathrm{dm}^{3} / \mathrm{h}$. Triolein was treated for up to $10 \mathrm{~h}$. The oxidized samples were cooled immediately after the oxidation and stored under nitrogen below $-18{ }^{\circ} \mathrm{C}$.

Derivatization with 2,4-dinitrophenylhydrazine (DNPH) To $1 \mathrm{~cm}^{3}$ of the oxidized oil samples $4 \mathrm{~cm}^{3}$ of acetonitrile was added and mixed with $3 \mathrm{~cm}^{3}$ of the reagent 2,4-DNPH $\left(3.48 \mathrm{mg} / \mathrm{cm}^{3}\right)$. The reaction mixture was kept in the dark for $1 \mathrm{~h}$. After completion of the reaction, $2 \mathrm{~cm}^{3}$ ethyl acetate was added for extraction and $1 \mathrm{~g} \mathrm{KCl}$ for better phase separation. This mixture was thoroughly shaken for $30 \mathrm{~s}$ and centrifuged for phase separation. The organic layer was analysed without further treatment by HPLC.

Liquid chromatography-mass spectrometry condition for aldehydes identification

The analyses of the DNPH derivatives of the carbonyls formed during oxidation were done by HPLC (Agilent 1100 , Waldbronn, Germany) using a reversed phase column (Kinetex, EVO C18, $150 \times 3 \mathrm{~mm}, 5 \mu \mathrm{m}$, Phenomenex, Aschaffenburg, Switzerland). For elution a gradient was used starting with methanol $(45 \%)$, water (30\%), and acetonitrile (25\%) changing to methanol (6\%), water (4\%), and acetonitrile (90\%) linearly within $15 \mathrm{~min}$. The absorption of the eluent was measured at $400 \mathrm{~nm}$ for the presence of the DNPH derivatives.

For mass selective detection, a QTRAP 2000 (AB Sciex, Framingham, MA, USA) was used. Ionization was done using the APCI mode with a gas drying temperature of $250{ }^{\circ} \mathrm{C}$, capillary voltage of $4000 \mathrm{~V}$, and a fragmentor potential of $150 \mathrm{~V}$. 


\section{Analyses of $\alpha$-tocopherol and $\beta$-carotene}

For the analyses of $\alpha$-tocopherol and $\beta$-carotene $25 \mathrm{mg}$ of the oil (triolein, triolein with $\beta$-carotene and triolein with $\alpha$-tocopherol) was extracted with $1 \mathrm{~cm}^{3}$ of methanol in $2-\mathrm{cm}^{3}$ reactions vials (Eppendorf, Wien, Austria). The samples were shaken for 2 min vigorously and centrifuged. Under these conditions, both $\alpha$-tocopherol and $\beta$-carotene were extracted quantitatively. The methanolic extract was used directly for HPLC analysis on a reversed phase column (Kinetex, EVO C18, $150 \times 3 \mathrm{~mm}, 5 \mu \mathrm{m}$, Phenomenex, Aschaffenburg, Switzerland) using a flow of $0.6 \mathrm{~cm}^{3} / \mathrm{min}$. $\alpha$-Tocopherol was separated isocratically using 5\% water in methanol detecting it at $292 \mathrm{~nm}$. $\beta$ Carotene was chromatographed with $100 \%$ acetonitrile with detection at $450 \mathrm{~nm}$.

Acknowledgements Open access funding provided by Graz University of Technology. This work was supported by Ministry of Research, Technology and Higher Education of the Republic of Indonesia.

Open Access This article is distributed under the terms of the Creative Commons Attribution 4.0 International License (http:// creativecommons.org/licenses/by/4.0/), which permits unrestricted use, distribution, and reproduction in any medium, provided you give appropriate credit to the original author(s) and the source, provide a link to the Creative Commons license, and indicate if changes were made.

\section{References}

1. Rohr-Udilova NV, Stolve K, Sagmeister S, Nohl K, SchulteHermann R, Grasl-Kraupp B (2008) Mol Nutr Food Res 52:352
2. Böhm T, Berger H, Nejabat M, Riegler T, Kellner F, Kuttke M, Sagmeister S, Bazanella M, Stolze K, Daryabeige A, Binther N, Murkovic M, Wagner KH, Schulte Hermann R, Rohr-Udilova N, Huber W, Grasl-Kraupp B (2013) J Hepatol 59:563

3. Zeb A, Murkovic M (2013) Food Res Int 50:534

4. Zeb A, Murkovic M (2011) Food Chem 127:1584

5. Farhoosh R, Pazhouhanmehr S (2009) Food Chem 114:1002

6. Angerosa F (2002) Eur J Lipid Sci Technol 104:639

7. Frankel EN (2005) Lipid oxidation, 2nd edn. Woodhead, Philadelphia, p 76

8. Schneider C, Porter NA, Brash AR (2008) J Biol Chem 283:15539

9. Schulte E (2002) Anal Bioanal Chem 372:644

10. Mottram HR, Woodbury SE, Evershed RP (1997) Rapid Comm Mass Spectrom 11:1240

11. Ochs S de M, Fasciotti M, Netto, ADP (2015) J Spectrosc 2015:1

12. Potter W, Karst U (1996) Anal Chem 68:3354

13. Mandel J (1984) The statistical analysis of experimental data. Dover publications Inc, New York

14. Feron VJ, Til HP, de Vrijer F, Woutersen RA, Cassee FR, van Bladeren PJ (1991) Mutat Res 259:363

15. Qu YH, Xu GX, Zhou JZ, Chen TD, Zhu LF, Shields PG, Wang HW, Gao YT (1992) Mutat Res 298:105

16. Ruiz-Méndez MV (2003) Refining of olive and pomace oils. In: Aparicio R, Harwood J (eds) Olive oil manual. AMV Ediciones and Mundi-Prensa, Madrid, p 563

17. Subramanian R, Nakajima M (1997) J Am Oil Chem Soc 74:971

18. Wan PJ, Pakarinen DR, Miscella RJ Sr (1996) J Am Oil Chem Soc 73:815

19. Katragadda HR, Fullana A, Sidhu S, Carbonell-Barrachina AA (2010) Food Chem 120:59

20. Sarkar A, Golay PA, Acquistapace S, Craft BD (2015) Int Food Sci Technol 50:666

21. Budilarto ES, Eldin AK (2015) Eur J Lipid Sci Technol 117:1025

22. Murkovic M, Wiltschko D, Pfannhauser W (1997) Fett/Lipid 99:165

23. Ooi CK (1999) PORIM Bull 338:29 